\title{
1 The precision problem in conservation and restoration
}

2

3 J. Kevin Hiers ${ }^{1 *}$, Stephen T. Jackson ${ }^{2}$, Richard J. Hobbs ${ }^{3}$, Emily S. Bernhardt ${ }^{4}$, Leonie E.

$4 \quad$ Valentine ${ }^{3}$

$5 \quad{ }^{1}$ Wildland Fire Science Program, Tall Timbers Research Station, Tallahassee, FL 32312,

6 USA.

$7 \quad{ }^{2}$ Department of the Interior Southwest Climate Science Center, U.S. Geological Survey,

8 Tucson, AZ 85721, USA and Department of Geosciences, University of Arizona, Tucson, AZ

9 85721, USA.

$10{ }^{3}$ School of Plant Biology, University of Western Australia, Crawley, WA 6009, Australia.

$11{ }^{4}$ Biology Department, Duke University, Durham, NC 27708, USA.

$12 *$ Corresponding Author: J. Kevin Hiers, 13093 Henry Beadel Dr., Tall Timbers Research

13 Station, Tallahassee, FL 32312 (USA); jkhiers@ ttrs.org; (office) 850.893.4153 x255 
Hiers et al. - The Precision Problem in Conservation

\section{Abstract}

2 Within the varied contexts of environmental policy, conservation of imperilled species

3 populations, and restoration of damaged habitats, an emphasis on idealized optimal

4 conditions has led to increasingly specific targets for management. Overly precise

5 conservation targets can reduce habitat variability at multiple scales, with unintended

6 consequences for future ecological resilience. We describe this dilemma in the context of

7 endangered species management, stream restoration, and climate-change

8 adaptation. Inappropriate application of conservation targets can be expensive, with marginal

9 conservation benefit. Reduced habitat variability can limit options for managers trying to

10 balance competing objectives with limited resources. Conservation policies should embrace

11 habitat variability, expand decision space appropriately, and support adaptation to local

12 circumstances to increase ecological resilience in a rapidly changing world. 
Hiers et al. - The Precision Problem in Conservation

\section{Can Precision be a Prescription for Failure?}

Ecological restoration and conservation are beset with an increasingly important paradox: narrowly defined restoration or conservation targets, intended to ensure successful outcomes, often lead to misdirected efforts and even outright failures. As an example, the Red-Cockaded Woodpecker (Picoides borealis) inhabits fire-maintained pine forests of the southeastern United States, and is endangered owing to widespread habitat loss and conversion; currently, less than 3\% of its original preferred habitat, Pinus palustris forest, remains intact $[1,2]$. Its plight was exacerbated by removal or mortality of old growth, cavity-bearing trees, which are preferred for roosting and nesting, and by fire suppression, which leads to a dense hardwood subcanopy that is unfavourable for foraging [3]. Habitat management under the Endangered Species Act was initially based on a narrow definition of target-habitat characteristics $[4,5]$, which excludes significant existing habitat that is entirely suitable from the bird's perspective [6]. Conservation planning based on this narrow target continues to drive management for habitat properties that are more restrictive-and often more costly — than required to support healthy populations (Fig. 1).

A second example arises in a completely different set of systems and scales. River restoration projects across widely divergent ecosystem types are converging upon a narrow range of outcomes that interfere with underlying conservation goals [7] (Fig. 2). A dominant approach used for river restoration throughout the developed world is Natural Channel Design (NCD), a process used to engineer the dimension, form, and profile of degraded river habitats to achieve particular channel shapes, sinuosity, and stability [8]. NCD projects involve extensive - and expensive - earth-moving to reshape channels and reconnect rivers with their riparian areas $[9,10]$. Management agencies often pose strict controls over the success criteria and metrics by which such projects are judged. The tendency to construct 
single-thread, sinuous channels in nearly every landscape, regardless of the conditions of less degraded rivers nearby, has been blamed for several outright management failures [7, 11, 12].

These examples represent a widespread but little-recognized problem, in which overly precise policies and planning may interfere with conservation goals and desired outcomes.

The problem arises in multiple contexts, including endangered species protection, habitat restoration, and climate-change adaptation. Here, we discuss why application of overly precise targets may be attractive to scientists, managers, and policy-makers, present diverse examples illustrating how precision can lead to adverse conservation consequences, and argue that more flexible and decentralized approaches may result in more effective management in a changing environment.

\section{Precisionism and the Allure of Certainty}

Expectations of precision are widely and deeply rooted in conservation culture, in the underlying scientific disciplines, in the public and private organizations charged with management, and in the broader regional, national, and global polities within which conservation takes place. We suggest that these expectations may arise from a narrow empirical foundation (whereby policy targets are based on incomplete and sometimes idiosyncratic empirical data) which may contribute to a collective culture of "precisionism"1 in which outcome precision represents a hidden and unquestioned assumption in conservation and restoration efforts. Problems are particularly acute when overly precise prescriptions are established at broad policy or regulatory scales, leaving managers little discretion in interpretation and application.

\footnotetext{
${ }^{1}$ Not to be confused with the $20^{\text {th }}$ Century art movement of the same name.
} 
The attraction of narrowly circumscribed outcomes has many sources. Conservation, restoration, and natural-resource management are applied sciences deriving from ecology, genetics, hydrology, climatology, and other sciences. Precision is generally considered a virtue and necessity in the physical and biological sciences; in their training, scientists are taught to embrace convergent solutions to problems, and to design rigorous research that will force unambiguous answers. The natural world, however, does not always accommodate this viewpoint. The ecological literature is full of cases in which theory or models that were rigorously tested in one setting came up lacking in another. In fact, throughout its history, ecology has been marked by a tension between a search for broadly applicable or even universal principles and a focus on the contingent and even idiosyncratic details of local populations and ecosystems [13]. At its core, our concerns about precision are twofold: 1) overly prescriptive regulations, when applied to broad jurisdictions with limited local discretion, are leading to landscape homogenisation and 2) local precision in planning or regulatory prescription-writing is often unjustifiably extrapolated from scientific study elsewhere, leading to wasted resources or unanticipated outcomes. Controls and dynamics of an ecological system in a particular place and time may not precisely apply at a different locale or at a different time, and scientific resources are rarely sufficient to support intensive study of a species or ecosystem in more than a few specific settings.

Furthermore, many species, particularly threatened or endangered species, live today in restricted habitats, so identification of their environmental tolerances and requirements may already be artificially narrow. For instance, direct fossil evidence from a coastal cave on Kaua'i, Hawai'i, indicates that prior to human disturbance, a number of passerine bird and vascular plant species that grow today only in the remote mountains of the island were growing along the coast [14]. These species have much broader habitat niches than assumed, and in the absence of disturbance and exploitation can occupy a much larger portion of the 
island [15]. In another case, critical habitat designations and protection strategies for the Everglades snail kite (Rostrhamus sociabilis) were based on apparent habitat preferences for large marshlands [16]. However, during an extensive drought, the majority of birds sighted were using smaller, unprotected wetlands near urban areas, which played an important role in buffering species populations during a time of stress [17].

For simple, practical reasons, available scientific studies may systematically underestimate the range of conditions under which species populations or ecosystems can be sustained. In the case of the endangered black-capped vireo, management prescriptions based on limited scientific studies excluded or forced alteration of some of the most suitable habitats for the species $[18,19]$. Similarly, habitat management guidelines for the endangered Golden-cheeked warbler (Setophaga chrysoparia) indicated that it exclusively used oakjuniper forests with high canopy cover/closure [20], but subsequent studies found that the species was successful not only across a wide range of canopy densities, but also in other types of vegetation $[21,22]$. In these and other cases, artificial precision based on insufficient information led to management practices that worked against species conservation.

When science meets policy or practice, additional factors can narrow the focus of targets or objectives. Clear, precise, and quantifiable objectives are attractive to policymakers and managers, providing straightforward metrics to assess compliance and success. Specific goals and objectives are also a foundational principle of ecosystem management in applied ecology, creating an expectation of precision in conservation planning [23]. Guidelines that are unequivocal, easy to interpret, and uniformly applicable across diverse jurisdictions simplify management decisions and oversight, and provide bulwarks against controversy or litigation. Finally, narrowly prescriptive guidelines resonate with cultural expectations of scientific precision and environmental stationarity. 


\section{How Narrow Targets Can Hinder Conservation}

Precise conservation targets, however attractive from scientific or administrative standpoints, are often oversimplified when applied at policy or regulatory scales. They frequently fail to accommodate real-world variation and heterogeneity in properties of species populations, habitats, and ecosystems. Targets may rely on detailed vegetation or habitat descriptions drawn from restricted sampling in a static framework. By focusing on goals that are easy to measure, overly specific conservation targets have the potential to hinder conservation goals, and to cause net loss of suitable habitat and biological diversity by artificial homogenisation of conservation areas.

Once set in place, overspecified habitat targets for endangered species can be difficult to modify. For example, management for the Red-Cockaded Woodpecker (RCW) has focused on maintenance and restoration of longleaf pine forest with a very particular set of properties, including a narrow range of tree densities and sizes, cover of herbaceous understory and absence of subcanopy or mid-story trees [5]. This optimal habitat structure was originally based on a "niche gestalt" concept of exceptional habitat productivity [4]. This concept was codified into a regulatory approach called "the matrix" that used restrictive habitat parameters from limited sites to define optimal habitat [5, 24], despite some evidence of fitness under a wider range of conditions $[13,25]$. A detailed analysis of woodpecker habitat use indicates that the prescribed target habitat accounts for only a portion of the range of habitats actually used by the species (Box 1). While recent iterations of the recovery plan recognize some elements of habitat variability relative to regulatory suitability [5], managers are frequently still required to alter forests that currently support healthy RCW populations to match narrower habitat prescriptions [26]. 
In practice, many conservation resources are managed for multiple objectives, including societal constraints. Narrow and inflexible management prescriptions designed for one purpose can lead to habitat homogenization that compromises the outcome for other conservation objectives. For example, the endangered seed-eating Carnaby's Cockatoo (Calyptorhynchus latirostris) relies on remnant native vegetation in southwestern Australia [27]. Banksia woodland in and around the Perth metropolitan area is nominally managed for multiple purposes, including cockatoo conservation. However, current management practice in the highly flammable Banksia woodlands emphasizes high-frequency fire aimed at reducing fuel accumulation and minimizing risk to property [28]. These practices lead to habitat homogenization, actively eliminating older patches of Banksia woodland, which happen to be the most productive habitats for cockatoo foraging (Fig. 1). Larger cockatoo populations could potentially be sustained in a more heterogeneous landscape, but this runs counter to current inflexible habitat management guidelines [27]. Additional examples of homogenization resulting from narrow prescriptions intended to balance multiple objectives are plentiful. In tallgrass prairie habitats of the Great Plains (USA), patterns of treatments for fire and grazing recommended to managers balancing the objectives of forage production and biodiversity [29] led to loss of critical within-patch variation and declines in native bird communities despite no increase in forage production from patch homogenization $[29,30]$.

Narrowly prescribed targets that fail to incorporate sufficient variability can also hamper adaptation to environmental change, particularly climate change (Box 2). Climate change in coming decades will inevitably force changes in local habitats, potentially shifting environmental baselines upon which current restoration projects rely. Climatic changes sufficient in magnitude to drive major physiognomic changes in vegetation are predicted to be widespread across a range of climate-change scenarios [31]. Similarly, hydrologic changes associated with climate or land use change will fundamentally alter the timing and intensity 
of floods and sediment loads away from the historic levels that are used to design restoration projects [32]. Many place-based habitat management plans will thus become anachronistic in the coming decades, and many may be rendered rapidly obsolete by short-term climate extremes and associated disturbances or transformations [32-36].

Although climate-adaptation planning is underway for many management units and regions, these efforts incur risks of over-precision in identifying future target-states. For example, niche-envelope models are increasingly applied to spatially precise downscaling of climate-model predictions to produce fine-scale forecasts of habitat suitability for species of concern. Accuracy of forecasts does not necessarily accompany precision, however, and the limits of spatial precision and accuracy of climate downscaling in complex terrain are not well known [37, 38]. Finally, emergence of climates lacking modern analogues [39] and contingency of future states of vegetation structure and composition on high-frequency climate variability [36] and biotic interactions [40] will inevitably cloud understanding of future habitat states in a changing environment (Box 2). Narrow, precise targets may ultimately become dead ends, rather than paths to future sustainability.

\section{Mimicking Nature in a Fuzzy Future}

Overly narrow policies and conservation objectives are part of a broader challenge facing conservation, which pitches traditional, relatively static, place- and species-based approaches against the increasing recognition of rapidly changing environments [41]. Conservation targets must not only be immediately effective, they must use available financial resources efficiently and provide flexibility as well as opportunity to bet-hedge and adapt to changing circumstances. This can be accomplished by adopting a more versatile approach to conservation that focuses on protection and restoration of heterogeneity and variability in ecological conditions $[29,30]$ rather than maintenance of static endpoints (Box 
1 2). While critical features of ecosystem management such as monitoring, expecting the unexpected, and adaptive management [23] can aid in addressing the precision problem, our perspective contrasts with the current ecosystem management application of sustainability principles to set conservation objectives. We assert that ecosystems, their underlying processes, and their constituent species may lack discretely defined management end-points whose full range of variability can be characterized into precise management objectivesecosystems represent a suite of moving targets. Sustainable conservation policy and practice must accommodate a wider array of current habitat variability, future outcomes, and endstates, compatible with core goals of fostering populations of threatened species [42] and maintaining critical ecosystem services [43]. Substitution of "open-ended" restoration or habitat creation for particular, discrete end-states is under discussion for some systems: the idea is to reinstate ecological processes and allow ecosystems to develop on their own [44, 45], as they have in the past [35]. Because variation within ecosystems will lead to innumerable potential outcomes, managing for variation is critical for defining a new realm of the "ecologically possible" without investing in artificial certainty of deterministic outcomes $[42,46]$.

While some species are undoubtedly restricted in their habitat requirements, others appear to be less demanding than supposed. Threatened species may adapt to changing environmental conditions in unexpected ways. For instance, the Florida scrub jay has recently been shown to use regenerating pastures as supplemental habitat [47], and Pinus radiata plantations in New Zealand have been adopted by native forest beetles in the recent absence of native forests [48]. Indeed, Carnaby's cockatoo utilizes exotic Pinus plantations as a seed resource [49], and snail kites forage on exotic snails [50] while benefiting from perches provided by exotic trees and shrubs [51]. Historically, many critical habitats are relatively young [35], indicating that many species have broader tolerances than might be apparent 
1 today [52]. Given that species distributions have changed in the past and are being altered in

2 the present as a result of climate change [53], it is critical to move beyond protection and

3 restoration of historic habitats to consider the broader arrays of environments in which

4 species of concern can be maintained [35, 52]. Our proposal builds on existing discussions

5 [54-57], but it goes further to embrace and leverage spatial heterogeneity, environmental

6 variability, and ecological processes simultaneously at policy and project scales.

Current practices in conservation policy and regulatory management may be poorly matched with the ecological complexity of the natural systems those practices aspire to conserve. Broadly applied regulatory prescriptions are likely to result in simplified ecosystems and landscapes--the opposite of what is required for maintaining management options and preparing for an increasingly uncertain future [58]. A careful balance is required between developing conservation and management policies that assist in conserving threatened species, habitats, and ecosystems, while at the same time maintaining and promoting variability of natural systems.

Although expanding conservation goals to encompass a more pluralistic management approach may appear unduly complicated $[55,56]$, it can actually make management easier by reducing unnecessary intervention. For the Red-Cockaded Woodpecker, an approach that recognises options outside the putative optimal habitat (Box 1) reduces the need for habitat manipulation, while at the same time addressing other conservation objectives [26]. Similarly for Carnaby's Cockatoo, moving from a uniform short-rotation fire regime to a more zoned approach may better serve the needs of property protection while also leading to longer unburnt habitat with more seed resources for cockatoos [27]. In river restoration, the adoption of a more pluralistic approach is likely to lessen the need for expensive engineering options and ongoing maintenance of engineered structures. Broadened targets can thus help managers make the best use of their resources; rather than being boxed into a single outcome, 
they can balance multiple costs and benefits. In view of the large uncertainties of climate change and ecological responses, managing for variability will impart resilience - species populations may be differentially buffered across habitat properties. Furthermore, careful study of how climate events affect species populations in different habitat settings provides opportunities for adaptive management (Box 2).

A high proportion of endangered species are now recognized as "conservation-reliant" - i.e., maintenance of viable populations of these species requires ongoing, species-specific intervention [59]. Similarly, many restored habitats require continual and costly efforts to maintain their permitted or regulated physical state, while little is invested in evaluating whether such efforts are achieving stated ecological goals $[9,60]$. As habitat loss and fragmentation continue, new stresses imposed by climate change are likely to increase the number of conservation-reliant species and habitats. Financial and human resources for conservation are already limited, and are unlikely to keep pace with increasing demands in the coming years. Thus, it is critically important to use resources efficiently, ensuring that only essential interventions are carried out and that they be maximally effective.

Aligning conservation practice with the complexity of the natural world poses many challenges. The push to obtain legal protection for a species or an ecosystem often leads to regulatory over-prescription for its management. Any attempt to broaden a definition may be perceived as a weakening of regulations, and thus a threat rather than an opportunity to adapt and incorporate new information. Strengthening protections is sometimes equated with increasingly narrow standards. Certainly, broader targets grant broader decision-space for managers, with potential for such expedient considerations as cost to weigh in, at least locally. Thus, dampening precisionism in prescription development may lead to increased tailoring of management options at the local scale through managers' flexibility to balance competing objectives at those scales. Obviously, regional or landscape perspectives are 
required to ensure a balanced and resilient network of suitable habitats [61]. Although unitary or overly narrow targets make it easier to formulate and enforce policy decisions, a more nuanced and ecumenical approach maps better onto the natural world, and is likely to yield greater conservation success ultimately at lower cost.

Recent work has focused on using spatial and temporal variation within the full range of ecological systems to bound the domain of possible outcomes for conservation management over time $[35,42,58]$. One such approach, the dynamic reference concept [42], is organized around the principle that current targets of ecosystem management and restoration are more dynamic than generally assumed, and their response to suites of changes over time will dictate the pace and direction of potential trajectories. An approach of this type, by focusing on the variation of ecosystem responses, rather than idealized or mean condition (i.e., precisionism), can provide a robust context to understand and yield desirable and realistic conservation outcomes in a rapidly changing future. This approach builds on the conceptual foundations of ecosystem management [23], but emphasizes variability and flexible response to change as paramount elements in conservation efforts. This dynamic approach to conservation management fundamentally contrasts with umbrella-species approaches to conservation: in novel environments and future contexts, the habitat relations of umbrella species, indicator species, and indeed all other species, are likely to change, just as they have in the past $[35,40,62]$.

In summary, accumulating scientific understanding of species biology, ecosystem processes, and environmental history indicates that the world is more complex than our conservation policies or management recommendations often assume. This mismatch between reality and policy is leading to wasted resources, misguided efforts, and potential failures in our efforts to conserve and restore nature, and these will only become more prevalent in the face of ongoing climate change. Managers have limited discretion to work 
8

within more realistic frameworks. The broader policy frameworks must evolve to allow more rapid adaptation to changing circumstances and quicker adoption of better information as it becomes available. This evolution will require continual rethinking and dialogue among scientists, conservationists, managers, policymakers, legislators, and lawyers. These dialogues must take place at many levels, employing approaches (e.g., scenario planning, decision analysis) that foster effective communication and ensure that participants step outside the prison of precisionism to see the broader possibilities that may lie beyond.

Acknowledgements: This paper derived from breakfast discussions at The Bean in Bainbridge, Georgia, as part of the Ichauway Conference on 'Managing future ecological change in the Southeast', sponsored by the Joseph W. Jones Ecological Research Center, the U.S. Forest Service, and the U.S. National Science Foundation. We thank Rick Anderson and Rob Sutter for contributing to the discussions, and the owners and employees of The Bean for indulging our lively early-morning deliberations. We also thank Carolyn Enquist, Shannon Farrell, Stephen Gray, Nancy Green, Teresa Krause, and Gregor Schuurman for comments and discussion. We dedicate this paper to the memory of Robert J. Mitchell (1955-2013).

\section{References}

1. Conner, R. N. et al. (2001) The Red-Cockaded Woodpecker: Surviving in a FireMaintained Ecosystem, University of Texas Press

2. Frost, C. C. (1993) Four centuries of changing landscape patterns in the longleaf pine ecosystem. In Proceedings of the Tall Timbers Fire Ecology Conference (Hermann, S.M., Ed.), pp. 17-43, Tall Timbers Research Station 
$13 . \quad$ Rudolph, D. C. et al. (2007) Red-cockaded woodpecker foraging behaviour. Wilson J.

2

3 Ornithol. 119, 170-180

4. James, F. C. et al. (2001) Ecosystem management and the niche gestalt of the RedCockaded Woodpecker in longleaf pine forests. Ecol. Appl. 11, 854-870

5. United States Fish and Wildlife Service (2003) Recovery Plan for the Red-Cockaded Woodpecker (Picoides borealis). U.S. Fish and Wildlife Service, Atlanta

6. McKellar, A. E. et al. (2014) Geographic variation in fitness and foraging habitat quality in an endangered bird. Biol. Conserve. 175, 52-64

7. Kondolf, G. M (2006) River restoration and meanders. Ecol. Soc. 11, 42-60

8. Rosgen, D. L. (2006) River restoration using a geomorphic approach for natural channel design. In Proceedings of the Eighth Federal Interagency Sedimentation Conference, April 2-6, Reno

9. Bernhardt, E.S. et al. (2005) Synthesizing US River Restoration efforts. Science 308, 636-637

10. Nagle, G. (2007) Evaluating ‘natural channel design’ stream projects. Hydrol. Process. 21, 2539-2545

11. Smith, S. M. and Prestegaard, K. L. (2005) Hydraulic performance of a morphologybased stream channel design. Water Resour. Res. 41, DOI:10.1029/2004WR003926

12. Wilcock, P.R. and Parker, G. (2006) Research, coordination, and open-source models to improve stream restoration practice. In Proceedings of the 8th Federal Interagency Sedimentation Conference. April 2-6, Reno

13. Reiners, W.A. and Lockwood, J.A. (2010) Philosophical Foundations for the Practice of Ecology, Cambridge University Press

14. Burney D.A. et al. (2001) Fossil evidence for a diverse biota from Kaua $i$ and its transformation since human arrival. Ecol. Monogr. 71, 615-641 
1 15. Burney, D.A. and Burney, L.P. 2007. Paleoecology and "inter-situ" restoration on

16. Bennetts, R.E. et al. (1994) The snail kite in the Florida Everglades: a food specialist in a changing environment. In Everglades: The Ecosystem and Its Restoration (Davis, S. M. and Ogden, J. C., eds), pp. 507-532, St. Lucie Press

17. Takekawa, J. E. and Beissinger, S. R. (1989). Cyclic Drought, Dispersal, and the Conservation of the Snail Kite in Florida: Lessons in Critical Habitat. Conserv. Biol. $3,302-311$

18. McFarland, T.M. et al. (2013) A Range-wide Survey of the Endangered Black-capped Vireo in Texas. Southeast. Nat. 12, 41-60

19. Pope, T. L. et al. (2013) Woodlands as Quality Breeding Habitat for Black-Capped Vireos. J. Wildlife Manage. 77, 994-1001

20. Klassen, J. A. et al. (2012) Canopy characteristics affect reproductive success of golden-cheeked warblers. Wildl. Soc. Bull. 36, 54-60

21. Camponizzi, A. J. et al. (2012) Species conservation at a broad spatial scale: reproductive success of golden-cheeked warblers across their breeding range. Wildl. Soc. Bull. 36, 440-449

22. Farrell, S. L. et al. (2012) Conspecific cues and breeding habitat selection in an endangered woodland warbler. J. Animal Ecol. 81, 1056-1064

23. Christensen, N. L. et al. (1996) The Report of the Ecological Society of America Committee on the Scientific Basis for Ecosystem Management. Ecol. Appl. 6, 665691

24. Lipscomb, D.J. and Williams, T.M. (2006) A GIS tool for evaluating the impact of proposed cuts on red-cockaded woodpecker habitat. In Proceedings of the 5th 
Hiers et al. - The Precision Problem in Conservation

Southern Forestry and Natural Resource GIS Conference, (Prisley, S., Bettinger, P., Hung, I. K. and Kushla, J. eds) pp. 139-147, University of Georgia

25. Walters, J. R. et al. (2002) Defining quality of red-cockaded woodpecker foraging habitat based on habitat use and fitness. J. Wildlife Manage. 66, 1064-1082

26. Hiers J. K. et al. (2014) The ecological value of retaining pyrophytic oaks in longleaf pine ecosystems. J. Wildlife Manage. 78, 383-393

27. Valentine, L. E. et al. (2014) Time since fire influences food resources for an endangered species, Carnaby's cockatoo, in a fire-prone landscape. Biol. Conserv. $175,1-9$

28. Wilson, B.A. et al. (2014) Mediterranean ecosystems: a case study in Banksia woodlands in Western Australia. Pac. Cons. Biol. 20, 57-74

29. Fuhlendorf, S.D. et al. (2006) Should heterogeneity be the basis for conservation? Grassland bird response to fire and grazing. Ecol. Appl. 16, 1706-1716

30. Fuhlehdorf, S. D. and Engle D. M. (2004) Application of the fire-grazing interaction to restore a shifting mosaic on tallgrass prairie. J Applied Ecol. 41, 604-614

31. Williams, J.W. et al. (2007) Projected distributions of novel and disappearing climates by 2100 AD. Proc. Natl. Acad. Sci. 104, 5738-5742

32. Niezgoda, S.L. and Johnson, P.A. (2005) Improving the urban stream restoration effort: identifying critical form and processes relationships. Environ. Manage. 35, $579-592$

33. Allen, C.D. et al. (2010) A global overview of drought and heat-induced tree mortality reveals emerging climate change risks for forests. Forest Ecol. Manag. 259, $660-684$

34. Swetnam, T.W. et al. (1999) Applied historical ecology: using the past to manage for the future. Ecol. Appl. 9, 1189-1206 
35. Jackson, S. T. (2012) Conservation and Resource Management in a Changing World: Extending Historical Range of Variation Beyond the Baseline. In Historial Environmental Variation in Conservation and Natural Resource Management (Wiens, J. A., Hayward, G. D., Safford, H. D., and Giffen, C.M. eds), pp. 92-109, WileyBlackwell

36. Jackson, S.T., et al. (2009) Ecology and the ratchet of events: climate variability, niche dimensions, and species distributions. Proc. Natl. Acad. Sci. 106, 19685-19692

37. Guttman, E.D. et al. (2012) A comparison of statistical and dynamical downscaling of winter precipitation over complex terrain. J. Climate 25, 262-281

38. Littell, J.S. et al. (2011) Managing uncertainty in climate-driven ecological models to inform adaptation to climate change. Ecosphere 2, DOI:10.1890/ES11-00114.1

39. Williams, J.W. and Jackson, S.T. (2007) Novel climates, no-analog communities, and ecological surprises. Front. Ecol. Environ. 5, 475-482

40. Jackson, S.T. and Blois, J.L. (2015) Community ecology in a changing environment: perspectives from the Quaternary. P. Natl. Acad. Sci. 112, 4915-4921

41. Heller, N. E. and Hobbs, R. J. (2014) Development of a Natural Practice to Adapt Conservation Goals to Global Change. Conserv. Biol. 28, 696-704

42. Hiers, J. K. et al. (2012) The dynamic reference concept: measuring restoration success in a rapidly changing no-analogue future. Ecological Rest. 30, 27-36

43. Tallis, H. et al. (2008) An ecosystem services framework to support both practical conservation and economic development. Proc. Natl. Acad. Sci. 105, 9457-9464

44. Hughes, F. M. R., et al. (2011) Monitoring and evaluating large-scale, 'open-ended' habitat creation projects: A journey rather than a destination. J. Nat. Conserv. 19, $245-253$ 
45. Hughes, F. M. R., et al. (2012) When is open-endedness desirable in restoration projects? Restor. Ecol. 20, 291-295

46. Golliday, S. et al. (2016) Achievable future conditions as a framework for guiding forest conservation and management. Forest Ecol. Manag. 360, 80-96.

47. Davison, M. A. and Fitzpatrick, J. W. (2010) Role of human-modified habitat in protecting specialist species: A case study in the threatened Florida Scrub-Jay. Biol. Conserv. $143,2815-2822$

48. Pawson, S.M. et al. (2008) Non-native plantation forests as alternative habitat for native forest beetles in a heavily modified landscape. Biol. Conserv. 17, 1127-1148

49. Stock, W.D. et al. (2013) Pine as fast food: Foraging ecology of an endangered cockatoo in a forestry landscape. PLOS One 8, DOI:10.1371/journal.pone.0061145

50. Cattau, C. E. et al. (2010) Effects of an exotic prey species on a native specialist: Example of the snail kite. Biol. Conser. 143, 513-520

51. Chen, L. Y. (2001) Cost savings from properly managing endangered species habitats. Natural Areas J. 21, 197-203

52. Dawson, T. P. et al. (2011) Beyond Predictions: Biodiversity Conservation in a Changing Climate. Science 332, 53-5847

53. Stralberg, D. et al. (2009) Re-shuffling of species with climate disruption: A noanalog future for California birds? PLOS One 4, DOI:10.1371/journal.pone.0006825

54. Simberloff, D. (1998) Flagships, umbrellas, and keystones: Is single-species management passé in the landscape era? Biol. Conser. 83, 247-257

55. Lawler, J. J. et al. (2015), The theory behind, and the challenges of, conserving nature's stage in a time of rapid change. Conserv. Biol. 29, 618-629 
1 56. Caro, T. et al. (2009) Assessing the effectiveness of protected areas: paradoxes call

57. Burgman, M.A. et al. (2005) Managing landscapes for conservation under uncertainty. Ecology 86, 2007-2017

58. Jackson, S. T. and Hobbs, R. J. (2009) Ecological restoration in the light of ecological history. Science $325,567-569$

59. Scott, J. M. et al. (2010) Conservation-reliant species and the future of conservation. Cons. Letters 3, 91-97

60. Bernhardt, E. S. and Palmer, M. A. (2011) River restoration: the fuzzy logic of repairing reaches to reverse catchment scale degradation. Ecol. Appl. 21, 1926-1931

61. Hobbs, R. J. et al. (2014) Managing the whole landscape: historical, hybrid, and novel ecosystems. Front. Ecol. Environ. 12, 557-564

62. Perkins, M. W., et al. (2008) The importance of hardwood trees in the longleaf pine forest ecosystem for Sherman's fox squirrels. Forest Ecol. Manag. 255, 1618-1625

63. Jackson, S.T. and Overpeck, J.T. (2000) Responses of plant populations and communities to environmental changes of the Late Quaternary. Paleobiology 26, $194-220$

64. Scheffer, M. (2009) Critical Transitions in Nature and Society. Princeton University Press 
Hiers et al. - The Precision Problem in Conservation

\section{Figure Legends}

2 Fig. 1 The target habitat characteristics of suitable long-leaf pine habitat (A) for the Red-

3 Cockaded Woodpecker (B) may be overly narrow in southeastern USA. The current

4 prescribed regime of frequent burning in banksia woodlands $(C)$ reduces food availability for

5 the Carnaby's Cockatoo (D) in southwestern Australia. Photos by: J. Ariail, K. Rose, L

6 Valentine.

7 Fig. 2 The planform view of five rivers: (A) Clark Fork, MT, USA; (B) White Clay Creek,

8 MD, USA; (C) Spring Meadow, UK; (D) Skerne River, UK; (E) Kelly Branch, FL, USA,

9 shows similar sinuosity of channel shapes for natural channel design projects in very different

10 physiographic regions. Similarly, the cross section view of six restored rivers: (F) Little

11 Sandy Creek, KY, USA; (G) Burd Run, PA, USA; (H) Sandy Creek, NC, USA; (I) Uvas

12 Creek, CA, USA; (J) Spring Meadow, UK; (K) Cuneo Creek, CA, USA, is nearly standardized across diverse regions.

Fig. I (Box 1) A non-metric multidimensional scaling analysis of ecological monitoring vegetation data at Eglin AFB. Red triangles represent habitat that meets regional recovery guidelines for RCW; green circles are all habitats occupied by the RCW at Eglin AFB.

Recognizing this variation is suitable habitat will is critical for efficient management of the population.

Fig. II (Box 2) Diagram A represents a theoretical multivariate point-cloud of the physical environment at a particular location. Green boundaries represent the current local climatic envelope; blue boundaries represent the current regional climatic envelop; red boundaries are the current universal climatic envelop. Diagram B illustrates many possible trajectories for any current ecological system under climate change, represented by 4 scenarios: a state unresponsive to climate change; one that responds gradually and directionally over time; one 
Hiers et al. - The Precision Problem in Conservation

1 that rapidly becomes a new irreversible ecological state in response to a series of events; one 2 that responds as a tipping point to a single event by establishing a new, persistent state. 

Figure 1

$1 \quad$ Fig 1.

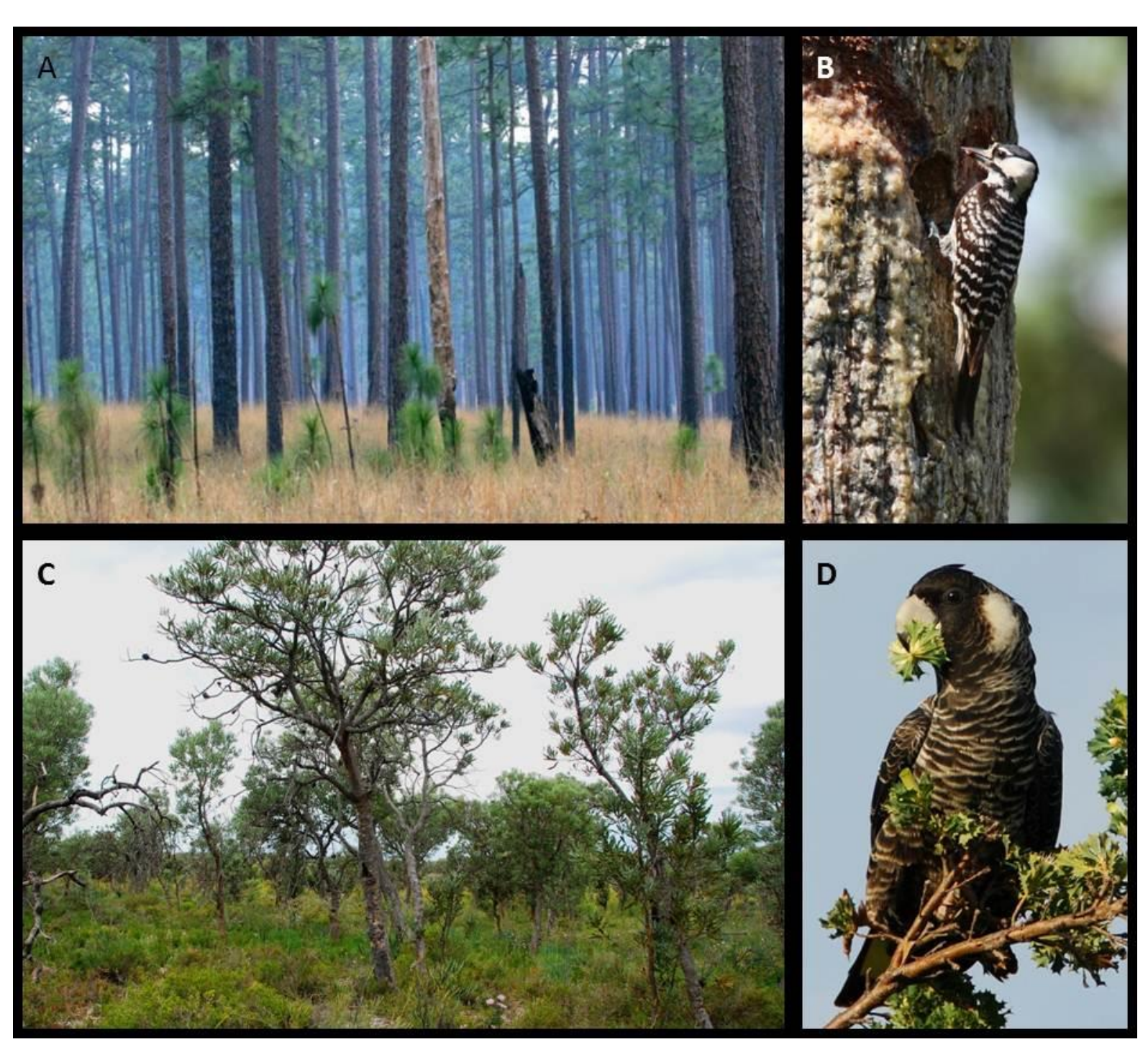




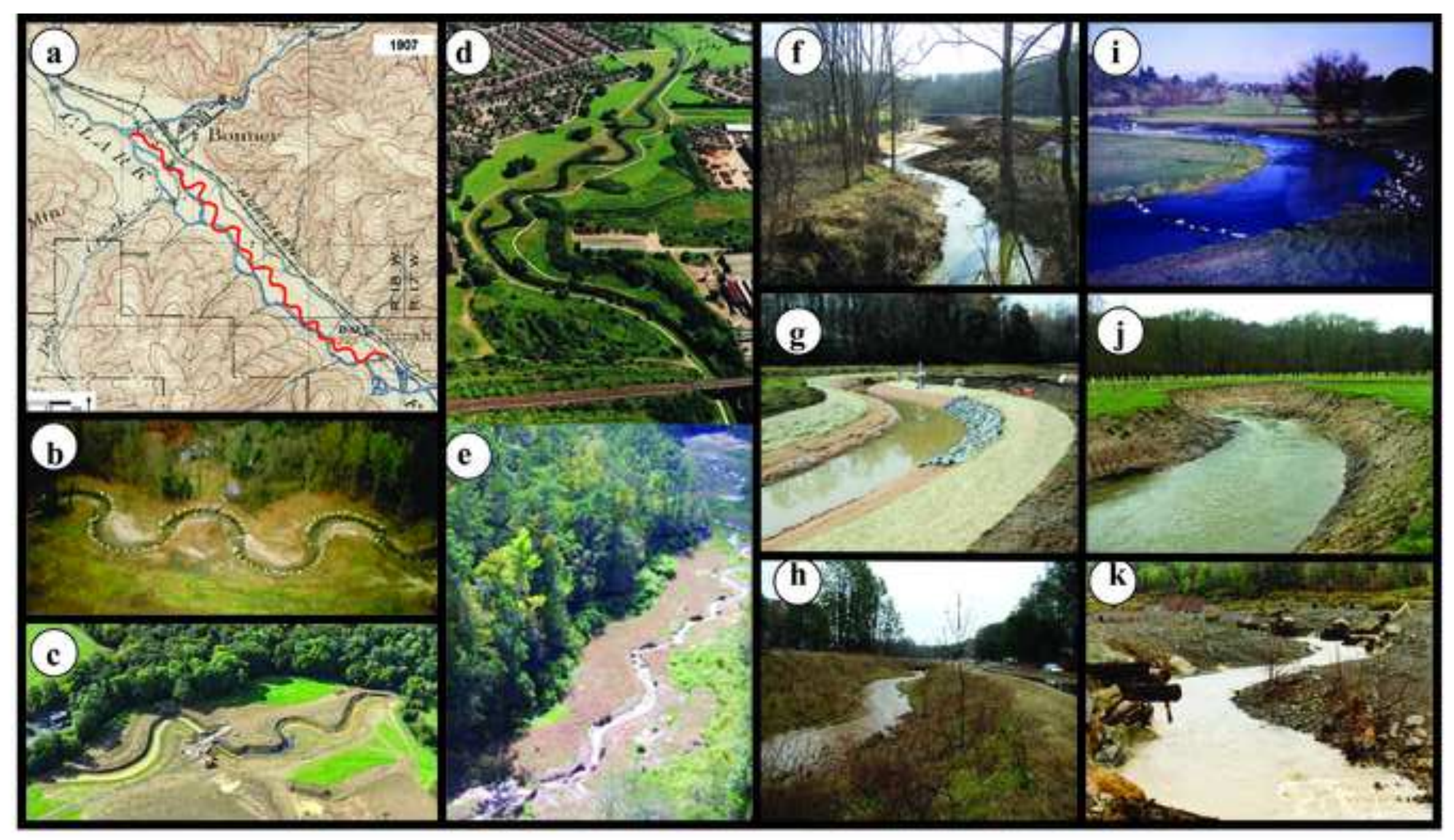




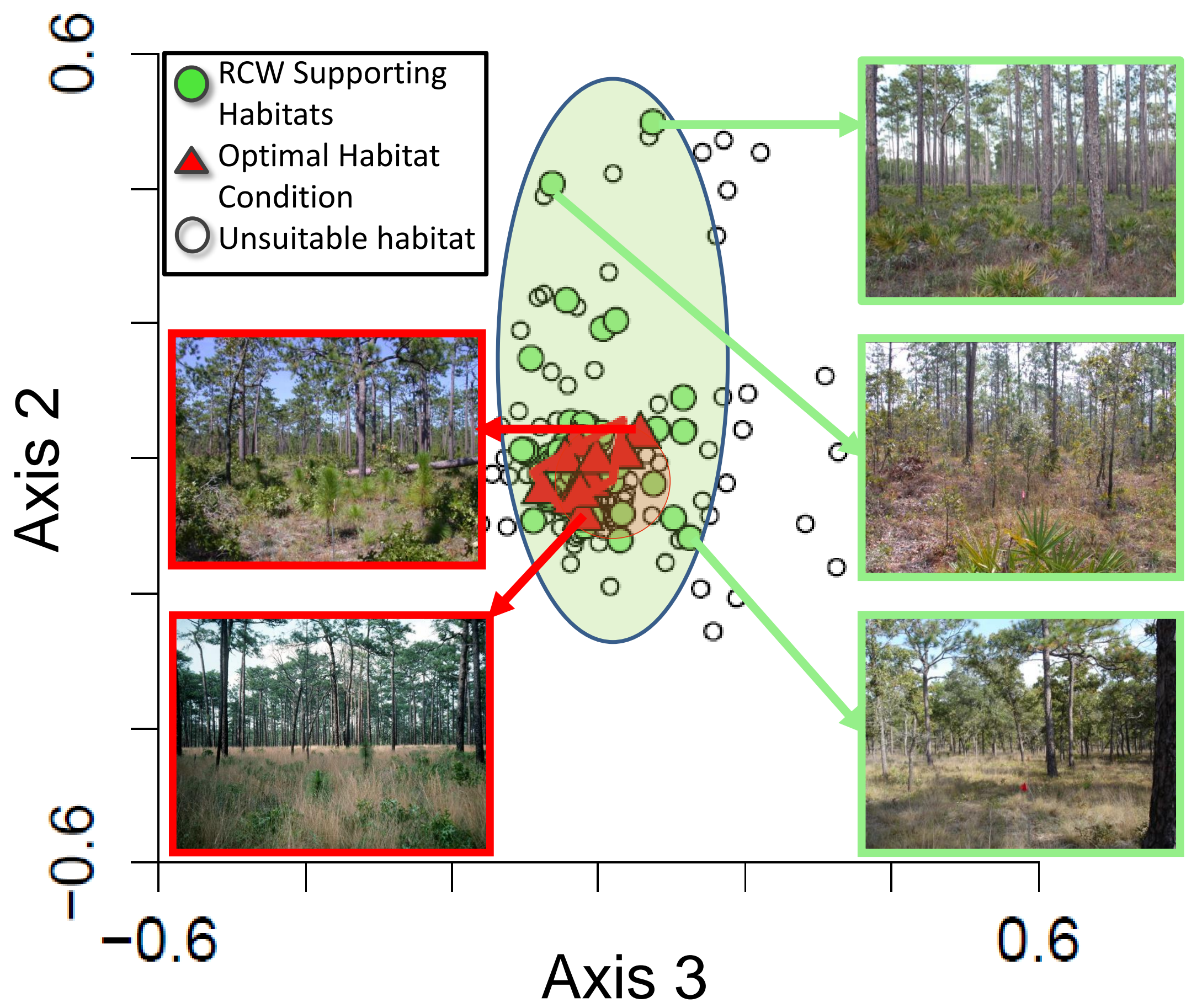


Fig. II

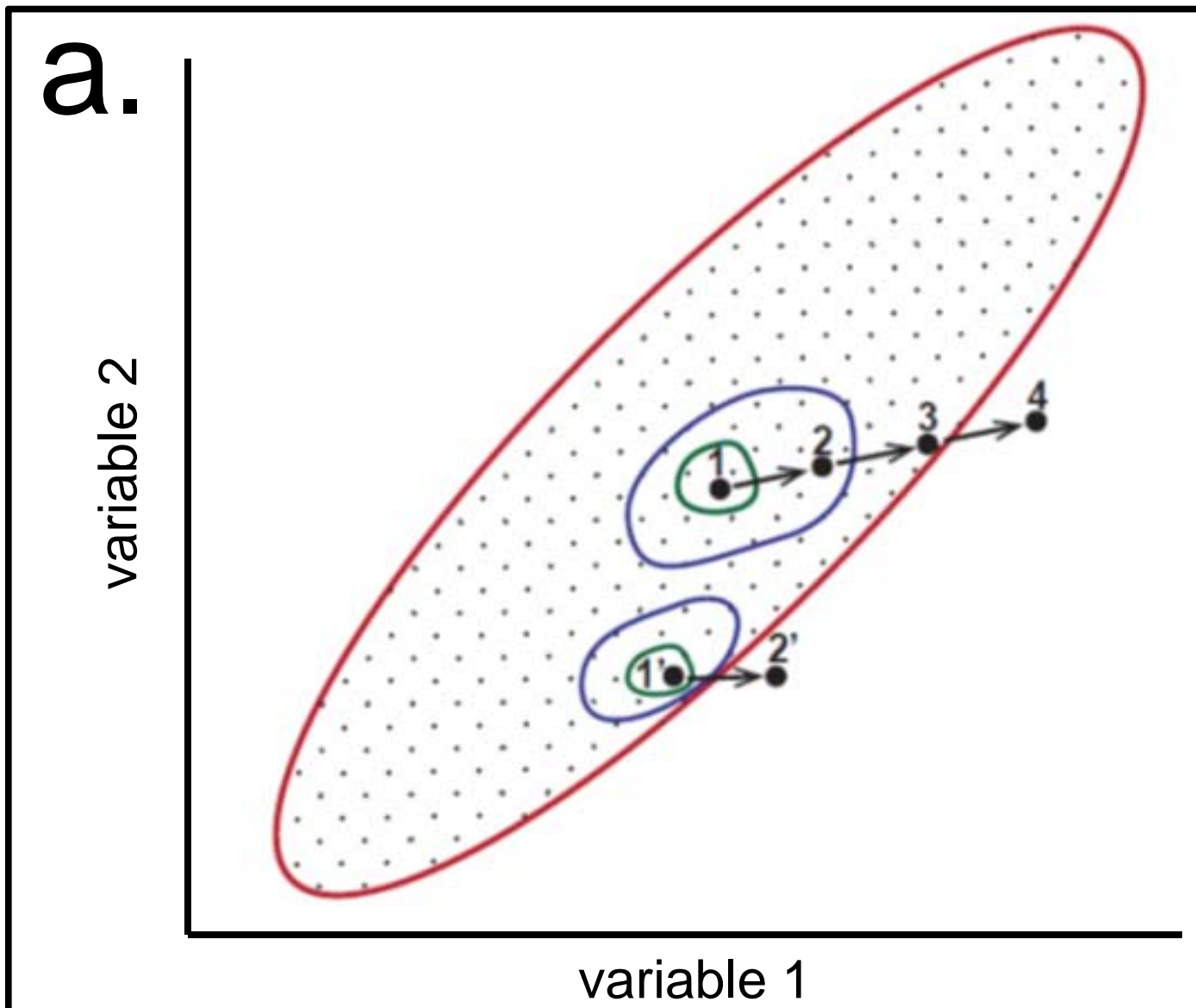

b.

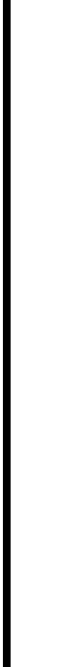

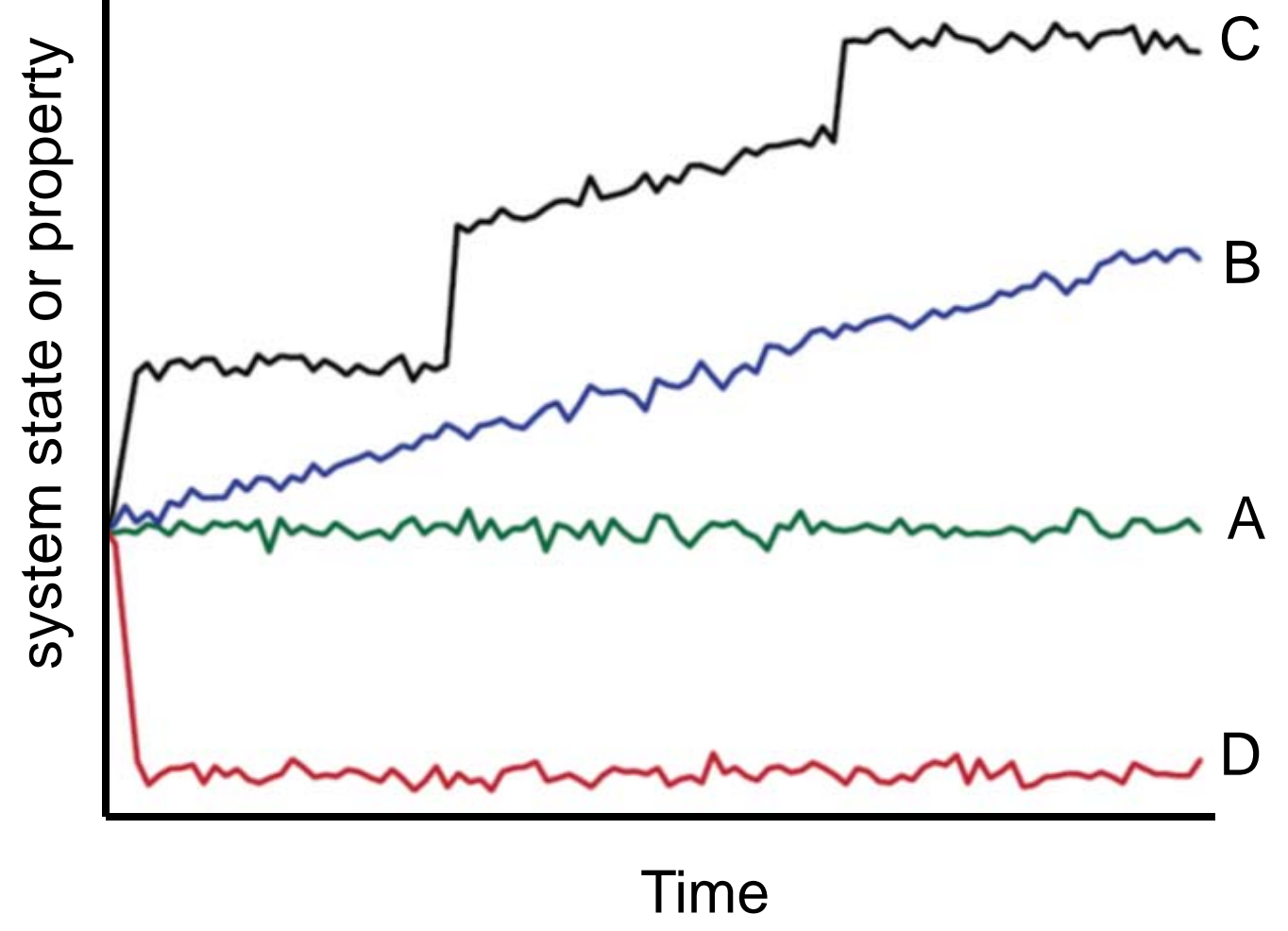




\section{Box 1. Beyond the Bullseye}

A non-metric multidimensional scaling analysis of ecological monitoring plots at Eglin Air Force Base [42] reveals that populations of the Red-Cockaded Woodpecker (RCW) occupy habitats far outside those defined as optimal [4] or originally detailed in the Recovery Plan for restoration of suitable RCW habitat $[5,7]$. The rapid growth of Eglin AFB's RCW population over the past decade now far exceeds legal recovery goals despite not meeting optimal habitat conditions. Simply put, the birds identify and exploit suitable habitats without reading the regulations [7]. Many populations are breeding successfully in a variety of stands well outside the optimal zone, but these sites remain targets of homogenisation towards idealized optimal habitats at Eglin AFB and elsewhere. Moreover, since not all habitats within the targeted "bullseye" are occupied, perfectly acceptable habitat (from the RCW's perspective) are under risk of conversion to conditions that may not support RCW populations, such as clearing "offsite" pine species in favour of young longleaf pine stands. While differences in habitat quality undoubtedly affects populations, many of the specific habitat parameters (e.g., growing-season fire, midstory oak density) not only comprise poor surrogates for RCW population success, then may compromise fitness in a variety of habitats. Habitat conversions are often accomplished through costly herbicide applications or mechanical treatments that reduce midstory stem densities [26]. In one case, midstory stems around RCW cluster sites in pocosin habitat in North Carolina were mechanically cleared to create preferred habitat structure. Pocosin is subject to more intense fires than other longleaf pine habitats, and subsequent wildfire burned through the cluster sites killing all cavity trees due to combustion of thinned debris and consumption of organic soil the mechanical midstory thinning. Clusters on adjacent lands that received no mechanical treatment were largely unaffected. Habitat homogenisation results in inefficient use 
of limited conservation resources and potential harmful impacts to other rare or threatened species that thrive on heterogeneity [62]. 


\section{Box 2. Indeterminacy of Ecological Targets under Climate Change}

Accurate characterization of targets for conservation under future climate change is hampered by several sources of indeterminacy in predicting future ecological states. The physical environment - a major source of uncertainty — comprises a multivariate point-cloud, with each point representing an individual site or locale (Fig. IIa). Environmental variables may be correlated within the point-cloud, but not all possible combinations of all variables are realized at any single time [63]. In the example figure, the variables are correlated in space (e.g., summer and winter temperatures), but do not necessarily change in the same direction or magnitude in time $[36,63]$. For a given site (e.g., point 1), the environment may vary from year to year or over decades within a local climate envelope (LCE) (green boundary in the figure).

Conservation targets are relatively straightforward if the environment stays within the LCE. However, climate change may drive variation outside the LCE (point 2). In this case, conservation targets are more difficult, but if the future climatic state is well-characterized, and is within the range of conditions observed elsewhere in the region (i.e., within the regional climate envelope (RCE) (blue boundary)) - for example, at lower elevation or latitude - then a target can be identified for management and characterized by space-for-time substitution. Additional climate change along the same trajectory can move the site outside the RCE (point 3), where regional analogs are not available. Conservation targets might be drawn from environmentally analogous sites in other regions, as long as the site remains within the universal climate envelope (UCE) (red boundary). Uncertainties are even greater in predicting both the environment of point 3 and the ecological states likely to result. Climate change along the same trajectory will eventually drive the site outside the UCE (point 4) (actually, the UCE itself shifts position [63]), whereupon there will be no current or historic analogs from which to predict and develop targets. 
Depending on the position of an individual site within realized climate space, and on the rate and directions of climate change, no-analog climates may arise rapidly (see 1`and 2` in Fig. IIa) according to projections for regions within the coming decades [31, 39]. Even with perfect characterization of future climate states, further indeterminacies are imposed by ecological processes and by ecological legacies of climate variability at interannual to multidecadal scales $[36,40]$. Fig. IIb shows four possible trajectories of an ecological system under climate change. In scenario A, the system state is unresponsive to climate change, allowing management for a narrowly prescribed target to be sustainable indefinitely. Under scenario B, the system evolves gradually in response to steady, unidirectional climate change. As long as the environmental trajectory and the equilibrium system-response can be predicted accurately and precisely, a series of evolving targets (or a single end-state target at some arbitrary future time) can be constructed and managed. In scenario $\mathrm{C}$, ecological stasis or equilibrium-change is punctuated by a series of events, each of which drives the system rapidly and irreversibly into a new state. Such events might include mass mortality from disturbance (fire, pest/pathogen outbreaks), which are often associated with transient climate events (e.g., extended, severe droughts), followed by expansion of other species. Periods between transformative events might be static or trendwise. Finally, scenario D portrays a singular event that drives the system to an alternate, persistent end-state that contrasts strongly with plausible alternatives or predictions. This 'surprise-state' scenario might involve, for instance, a severe, widespread disturbance followed by colonization of a persistent 'ecosystem transformer' [64]. Because individual site or system might follow any number of different trajectories, unitary targets will only be useful in short-term or static situations, while greater nimbleness and adaptive capacity may be more effective for management in the long run. 